Western University Scholarship@Western

1987

\title{
Search Intensity in Experiments
}

Glenn W. Harrison

Peter Morgan

Follow this and additional works at: https://ir.lib.uwo.ca/economicsresrpt

Part of the Economics Commons

Citation of this paper:

Harrison, Glenn W., Peter Morgan. "Search Intensity in Experiments." Department of Economics Research Reports, 8711. London, ON: Department of Economics, University of Western Ontario (1987). 
ISSN : 0318-725X

ISBN : 0-7714-0914-1

RESEARCH REPORT 8711

SEARCH INTENSITY IN EXPERIMLNTS

Glenn W. Harrison

Peter Morgan

Department of Economics

University of Western Ontario

London, Ontario, Canada

N6A $5 C 2$

August 1987

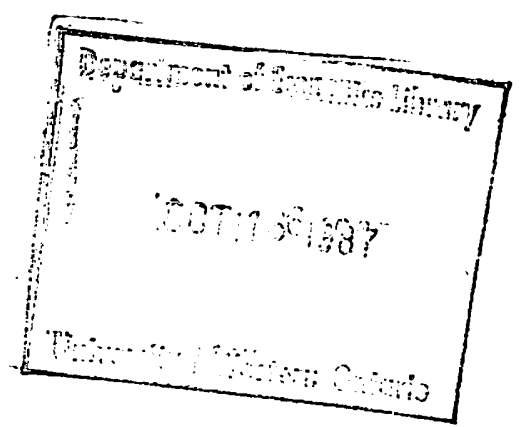




\section{SEARCH INTENSITY IN EXPERIMENTS}

\section{by}

Glenn W. Harrison and Peter Morgan ${ }^{*}$

August 1987

*Department of Economics, University of Western Ontario. We are grateful to the Social Sciences and Humanities Research Council of Canada for research support. 


\section{INTRODUCTION}

The theoretical literature on the search behaviour of workers and consumers typically considers three search strategies. These strategies are characterized by alternative assumptions about the temporal and atemporal intensity of search. The first strategy, described by stigler [1961, 1962], is the atemporally intensive fixed-sample-size strategy (FSS) which restricts the agent to collecting exactly one sample of contemporaneous of fers but allows him to choose the sample size. The second strategy, introduced by McCal1 [1970] and thoroughly reviewed by Lippman and McCal1 [1976], is the temporally intensive pure-sequential strategy (SEQ) which allows the agent to collect as many samples as he chooses but restricts the size of each to unity. The third strategy is the variable-sample-size strategy (VSS). This strategy is a generalisation of the first two since it allows the agent to sequentially choose both how many samples to take and the size of each sample. Descriptions of the VSS are given by Benhabib and Bul1 [1983], Gal, Landsberger and Levykson [1981], Morgan [1983] and Morgan and Manning [1985]. In this paper we report an experimental comparison and evaluation of these three search strategies.

Since the FSS and SEQ search strategies are special cases of the VSS strategy, it is obvious that the vSs strategy will always allow the agent an expected net payoff as large as those of the FSS and SEQ strategies. However, solving for the best FSS, SEQ, or VSS strategies are involved computational tasks. There is no guarantee that real agents are able to accurately compute 
such strategies even if the model is essentially correct in its description of the agent's goals and approach to the problem. A second question that must be faced, therefore, is how to decide if departures of observed behaviour from predicted behaviour should be attributed to a fundamental failure of the model or to the agent having only limited perceptive and computational abilities. We make these decisions by computing the theoretical opportunity costs for various deviations from the "optimal" strategies and asking when these departures are too expensive to be reasonably attributed to deficiencies in the agent's abilities. In taking this approach we are following a well established psychological literature dealing with "perceptual thresholds" (see Von Winterfeldt and Edwards [1982]).

The particular class of search problems used as a vehicle for the comparison and evaluation of the three strategies is that considered by Benhabib and Bull [1983, Section 2]. These problems were chosen because they are of considerable interest in their own right, are relatively simple to implement in an experimental environment, contain all the structure necessary for discriminating between the three strategies, and because the problems' expected net income maximand is a simple concept for experimental subjects to grasp.

The SEQ and FSS strategies have been subject to extensive experimental tests by psychologists and, to a lesser extent, by economists. The former literature has revealed a number of serious departures from optimal behaviour: see Connolly and Gilani [1982] and Connolly and Serre [1984] for reviews. Unfortunately these results cannot all be dismissed on the grounds that the subjects faced only non-monetary incentives and are hence non-salient. However, those experiments that did employ monetary rewards appear to suffer from a serious "flat-maxima" problem identified by Rapaport 
and Wallsten [1972; p. 169], Wendt [1969] and discussed in detail by Von Winterfeldt and Edwards [1982] [1986; pp. 420-447]. This problem refers to the absence of perceptually salient (opportunity) costs to sub-optimal decisions. Our experiments are designed to mitigate this problem, as discussed below.

Experimental economists have focussed primarily on the SEQ strategy: see Schotter and Braunstein [1981], Braunstein and Schotter [1982] and Cox and Oaxaca [1986]. A major difficulty with the Braunstein and Schotter SEQ experiments is the use of an infinite horizon theoretical model with finite (time) horizon experiments. This led Cox and Oaxaca [1986] to explicitly formulate and solve a finite horizon model of SEQ search. In their baseline experiment 30 subjects on average deviated from the optimal search horizon by 3.52 periods (the expected duration was 4.36 periods) for an average deviation in foregone payof $f$ of $\$ 0.413$ (the expected payoff was $\$ 1.344$ ). It is interesting to note that the expected-income-maximizing VSS and FSS strategies for these experiments provide expected incomes at least $45 \%$ higher than does the SEQ strategy. This is not to say that the study of the SEQ strategy alone is uninteresting, but to illustrate the value of examining the vSS and FSS search strategies.

The structure of the paper is as follows. In Section 2 we set out the formal structure of the search models examined. Section 3 provides details of the experimental procedure followed. Testable hypotheses and results are presented in Section 4. Conclusions are offered in Section 5.

\section{THE SEARCH PROBLEYS}

The class of problems considered here is that analysed by Benhabib and 
Buli [1983, Section 2]. The structure and notation are as follows:

A1. Time is divided into a known and finite number $T \geq 1$ of equal length periods denoted by $t \in\{1, \ldots, T\}$.

A2. At the beginning of period 1 the agent must search for at least one wage offer.

A3. For $T \geq 2$, at the beginning of any period $t \in\{2, \ldots, T\}$ an agent who is unemployed in period $t-1$ can choose from the mutually exclusive alternatives of

(a) searching for an acceptable wage offer, and

(b) accepting a wage offer just received.

A4. For $t \geq 3$, at the beginning of any period $t \in\{3, \ldots, T\}$ an agent who is employed in period $t-1$ can choose from the mutually exclusive alternatives of

(a) searching for an acceptable wage offer, and

(b) continuing to work at the same wage received in the previous period.

A5. The agent knows the probability distribution over the population of wage offers from which he may sample.

A6. The agent's discount rate is zero.

A7. There is no recall of wage offers not accepted at an earlier date.

A8. The agent's wages are his only source of income.

A9. In each period the agent faces the same sampling cost function, $c(n)$, where $n \geq 0$ denotes the sample size.

A10. If the agent accepts a wage offer $w$ at date $t$ then he receives $w$ in each of the $T-t+1$ remaining periods for which he chooses to remain in the job.

A11. The agent seeks to maximise his expected total wage earnings net of search costs. 
The reader is directed to Benhabib and Bull [1983] for the predictions of the model. Our primary interest here is to discover which, if any, of the FSS, SEQ, and VSS search strategies are consistent with the behaviour of the experimental subjects.

Using a computer program written to solve a wide variety of search problems, we selected parameter values which divided the problems faced by the experimental subjects into three classes. These are

CLASS 1: Problems for which theory predicts the best FSS strategy's expected value to be near to that of the optimal vss strategy and much higher than that of the best SEQ strategy;

CLASS 2: Problems for which theory predicts the best SEQ strategy's expected value to be near to that of the optimal vSS strategy and much higher than that of the best FSS strategy; and

CLASS 3: Problems for which theory predicts the optimal vSs strategy's expected value to be much higher than those of the best FSS and the best SEQ strategies.

The experimental subjects were faced with a total of 23 search problems from the above classes. Some employ a constant marginal cost sampling cost function $T C(n)=$ cn while others use an increasing marginal cost sampling cost function $\mathrm{TC}(n)=\mathrm{cn}^{4}$. The number of periods in the problems vary over $T=$ $2,4,6,8,16$. Four wage offer probability distributions were used in the construction of these problems. These are labelled as BETA1 to BETA4 and are illustrated in Figure 1 together with their parameters. In each distribution the wage offer variable $W=10 x$, where $X$ is distributed as a $\operatorname{Beta}(p, q)$ random variable. The reader will notice that the BETAl distribution is symmetric while BETA2 to BETA4 are increasingly right-skewed and less favourable 


\section{FIGURE 1}
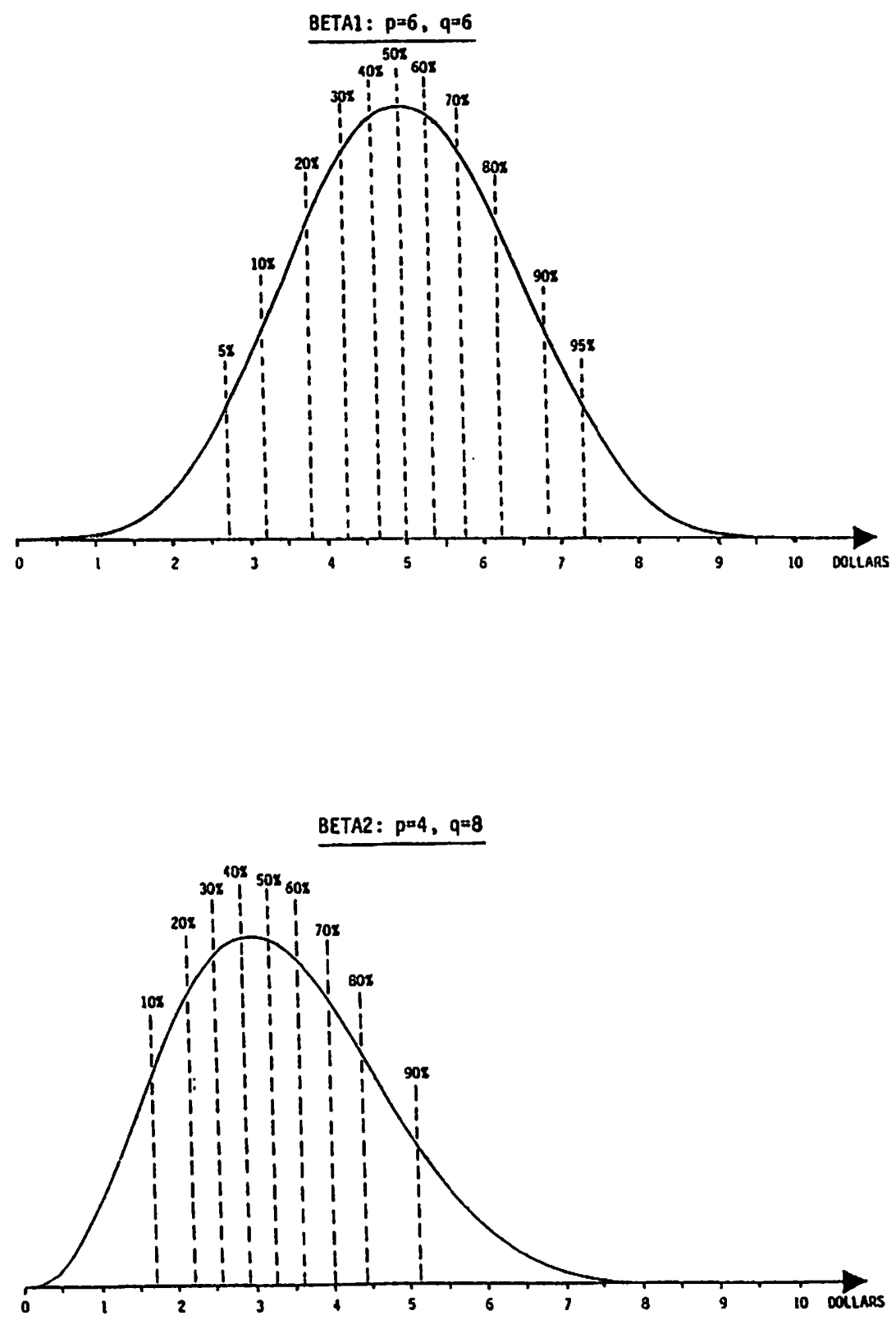

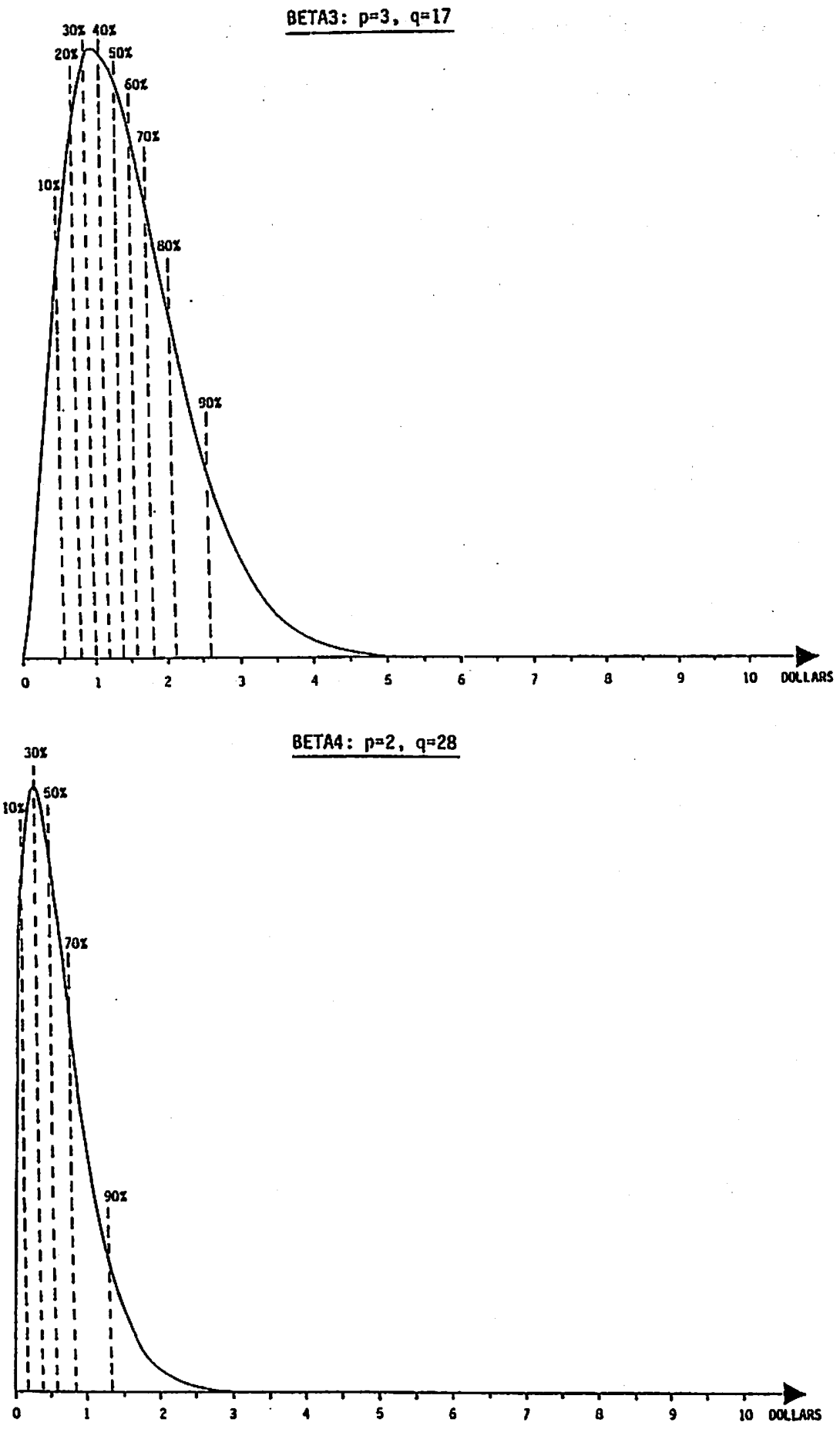
to the agent. Table 1 summarizes this experimental design.

The theoretically optimal vSS search strategy and the theoretically best SEQ and FSS search strategies for each of the problems considered are all reservation-wage strategies. Table 2 lists the theoretical predictions for all possible problems employing the BETA1 population. Space constraints restrict us to list the predictions and expected present value (EPV) for period 1 only. For example, an agent using a vSS strategy in problem 16 who faces a sampling cost function $T C(n)=0.05 n^{4}$, the wage offer distribution BETA1, and a decision horizon (T) of 4 periods will in theory accept any wage offer of $\$ 3.926$ or more when he has 3 periods remaining. If his current best wage offer is less than $\$ 3.926$ then theoretically he will continue to search by buying another 2 wage offers; the expected net value to him of continuing to search at that point is $\$ 18.085$. Alternatively, an agent using the theoretically best SEQ strategy in the paired problem 17 will accept any wage offer of $\$ 3.656$ or more when he has 3 periods left; the expected net value of continuing to search in a pure one-at-a-time sequential manner is $\$ 16.640$ at that point. Inspection of Table 2 reveals that the expected values of the three search strategies can vary considerably for the same problem.

In a very narrow sense Table 2 is all that is needed to decide if any of the three search strategies explain observed behavior. Tables A1-A3 in Appendix A report comparable predictions for the other three wage distribution populations. Table 44 reports complete predictions of optimal behavior for the 23 problems our subjects faced. For example, if we observe most of our agents taking samples of more than one offer at a time when they had the option to do so we could reject the pure-sequential model. Similarly, if we 
TABLE I

Experimental Design

\begin{tabular}{|c|c|c|c|c|c|c|c|}
\hline Problem & $\begin{array}{l}\text { Search } \\
\text { Strategy }\end{array}$ & Population & $\begin{array}{l}\text { Cost } \\
\text { Schedule }\end{array}$ & $\begin{array}{l}\text { Decision } \\
\text { Horizon }(T)\end{array}$ & $\begin{array}{l}\text { Optimal } \\
\text { Period I } \\
\text { Sample } \\
\text { Size (n) }\end{array}$ & $\begin{array}{l}\text { Strategy's } \\
\text { Expected } \\
\text { Present } \\
\text { Value (EPV,) }\end{array}$ & $\alpha_{1}$ \\
\hline 1 & vSS & BETA2 & $\$ 0.05 n^{4}$ & 8 & 2 & $\$ 32.636$ & - \\
\hline 2 & FSS & BETA2 & $0.05 n^{4}$ & 8 & 2 & 31.216 & 4.5 \\
\hline 3 & SEQ & BETA2 & $0.05 n^{4}$ & 8 & 1 & 29.794 & 9.5 \\
\hline 4 & vSS & BETA3 & $0.25 n^{4}$ & 6 & 1 & 10.695 & - \\
\hline 5 & FSS & BETA3 & $0.25 n^{4}$ & 6 & 1 & 9.722 & 10.0 \\
\hline 6 & VSS & BETAI & $0.50 \mathrm{n}$ & 2 & 2 & 5.289 & - \\
\hline 7 & SEQ & BETAI & $0.50 n$ & 2 & 1 & 5.000 & 5.8 \\
\hline 8 & vSS & BETA3 & $0.25 n$ & 4 & 7 & 7.764 & - \\
\hline 9 & SEQ & BETA3 & $0.25 n$ & 4 & 1 & 5.951 & 30.5 \\
\hline 10 & vSS & BETA4 & $0.05 n^{4}$ & 16 & 2 & 25.171 & - \\
\hline 11 & FSS & BETA4 & $0.05 n^{4}$ & 16 & 2 & 19.967 & 26.1 \\
\hline 12 & vSS & BETA3 & $0.50 n$ & 4 & 3 & 6.562 & - \\
\hline 13 & SEQ & BETA3 & $0.50 n$ & 4 & 1 & 5.627 & 16.6 \\
\hline 14 & vSS & BETA3 & $0.25 n^{4}$ & 8 & 1 & 15.507 & - \\
\hline 15 & FSS & BETA3 & $0.25 n^{4}$ & 8 & 1 & 13.711 & 13.1 \\
\hline 16 & vSS & BETAI & $0.05 n^{4}$ & 4 & 2 & 18.085 & - \\
\hline 17 & SEQ & BETAI & $0.05 n^{4}$ & 4 & I & 16.640 & 8.7 \\
\hline 18 & vSS & BETA3 & $0.50 n^{4}$ & 6 & 1 & 10.343 & - \\
\hline 19 & FSS & BETA3 & $0.50 n^{4}$ & 6 & 1 & 9.472 & 9.2 \\
\hline 20 & vSS & BETA3 & $0.10 n^{4}$ & 4 & 1 & 6.145 & - \\
\hline 21 & FSS & BETA3 & $0.10 n^{4}$ & 4 & 1 & 5.883 & 4.5 \\
\hline 22 & vSS & BETAI & $0.10 n^{4}$ & 4 & 2 & 17.280 & - \\
\hline 23 & SEQ & BETAI & $0.10 n^{4}$ & 4 & 1 & 16.586 & 4.2 \\
\hline
\end{tabular}

Note: $\alpha_{1}$ is the percentage gain in EPV, if the agent had been allowed to employ the optimal VSS for the entire decision horizon. 
TABLE 2

Theoretical Predictions for Alternative Search Strategies: BETAI Population

\begin{tabular}{|c|c|c|c|c|c|c|c|c|c|c|c|c|}
\hline $\begin{array}{l}\text { Cost } \\
\text { Schedule }\end{array}$ & $\begin{array}{l}\text { Decision } \\
\text { Horizon }(T)\end{array}$ & & Sequent & (SE & & & mple S & (FS & & Variabl & mple & (VSS) \\
\hline$==$ & $=0=x=x=x=0$ & $E_{1}{ }^{S} V_{1}^{S}$ & $\alpha_{1}^{s}$ & $n_{1}^{s}$ & $=c======$ & $=======$ & $\alpha{ }_{i=0}^{f}$ & $\eta_{===}^{f}$ & $=====$ & 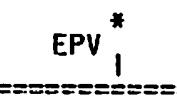 & $n_{1}^{*}$ & $=======$ \\
\hline$\$ 0.25 n$ & $\begin{array}{r}2 \\
4 \\
6 \\
8 \\
16\end{array}$ & $\begin{array}{l}\$ 5.250 \\
16.424 \\
28.247 \\
40.444 \\
92.930\end{array}$ & $\begin{array}{l}12.9 \% \\
24.1 \\
26.1 \\
26.8 \\
24.9\end{array}$ & $\begin{array}{l}1 \\
1 \\
1 \\
1\end{array}$ & $\begin{array}{l}\$ 0.0 \\
3.588 \\
4.143 \\
4.905 \\
5.751\end{array}$ & $\begin{array}{r}5.936 \\
20.389 \\
35.624 \\
51.253 \\
115.784\end{array}$ & $\begin{array}{l}0.0 \% \\
0.0 \\
0.0 \\
0.0 \\
0.3\end{array}$ & $\begin{array}{r}4 \\
8 \\
12 \\
16 \\
29\end{array}$ & $\begin{array}{l}\$ 0.0 \\
0.0 \\
0.0 \\
0.0 \\
0.0\end{array}$ & $\begin{array}{r}5.936 \\
20.389 \\
35.625 \\
51.268 \\
116.086\end{array}$ & $\begin{array}{r}4 \\
8 \\
12 \\
16 \\
26\end{array}$ & $\begin{array}{l}\$ 0.0 \\
4.338 \\
5.589 \\
6.200 \\
7.185\end{array}$ \\
\hline $0.50 n$ & $\begin{array}{r}2 \\
4 \\
6 \\
8 \\
16\end{array}$ & $\begin{array}{r}5.000 \\
16.154 \\
27.919 \\
40.112 \\
92.431\end{array}$ & $\begin{array}{l}5.8 \\
16.7 \\
19.5 \\
20.4 \\
19.6\end{array}$ & $\begin{array}{l}1 \\
1 \\
1 \\
1\end{array}$ & $\begin{array}{l}0.0 \\
3.504 \\
4.380 \\
4.858 \\
5.717\end{array}$ & $\begin{array}{r}5.289 \\
18.854 \\
33.348 \\
48.295 \\
110.407\end{array}$ & $\begin{array}{l}0.0 \\
0.0 \\
0.0 \\
0.0 \\
0.1\end{array}$ & $\begin{array}{r}2 \\
5 \\
7 \\
9 \\
17\end{array}$ & $\begin{array}{l}0.0 \\
0.0 \\
0.0 \\
0.0 \\
0.0\end{array}$ & $\begin{array}{r}5.289 \\
18.851 \\
33.357 \\
48.306 \\
110.536\end{array}$ & $\begin{array}{r}2 \\
5 \\
7 \\
9 \\
16\end{array}$ & $\begin{array}{l}0.0 \\
3.958 \\
5.206 \\
5.827 \\
6.843\end{array}$ \\
\hline $0.05 n$ & $\begin{array}{r}2 \\
4 \\
6 \\
8 \\
16\end{array}$ & $\begin{array}{r}5.450 \\
16.640 \\
28.509 \\
40.709 \\
93.330\end{array}$ & $\begin{array}{l}0.7 \\
8.7 \\
8.6 \\
8.9 \\
6.8\end{array}$ & $\begin{array}{l}1 \\
1 \\
1 \\
1 \\
1\end{array}$ & $\begin{array}{l}0.0 \\
3.656 \\
4.194 \\
4.943 \\
5.777\end{array}$ & $\begin{array}{r}5.489 \\
18.068 \\
30.647 \\
43.225 \\
96.210\end{array}$ & $\begin{array}{l}0.0 \\
0.1 \\
1.0 \\
2.6 \\
3.6\end{array}$ & $\begin{array}{l}2 \\
2 \\
2 \\
2 \\
3\end{array}$ & $\begin{array}{l}0.0 \\
0.0 \\
0.0 \\
0.0 \\
0.0\end{array}$ & $\begin{array}{r}5.489 \\
18.085 \\
30.952 \\
41.338 \\
99.670\end{array}$ & $\begin{array}{l}2 \\
2 \\
2 \\
2 \\
2\end{array}$ & $\begin{array}{l}0.0 \\
3.926 \\
4.902 \\
5.368 \\
6.161\end{array}$ \\
\hline $0.10 n^{4}$ & $\begin{array}{r}2 \\
4 \\
6 \\
8 \\
16\end{array}$ & $\begin{array}{r}5.400 \\
16.586 \\
28.444 \\
40.642 \\
93.230\end{array}$ & $\begin{array}{l}0.0 \\
4.2 \\
5.8 \\
6.5 \\
5.2\end{array}$ & $\begin{array}{l}1 \\
1 \\
1 \\
1 \\
1\end{array}$ & $\begin{array}{l}0.0 \\
3.639 \\
4.481 \\
4.934 \\
5.771\end{array}$ & $\begin{array}{r}5.400 \\
17.268 \\
29.847 \\
42.425 \\
92.740\end{array}$ & $\begin{array}{l}0.0 \\
0.1 \\
0.8 \\
2.0 \\
5.7\end{array}$ & $\begin{array}{l}1 \\
2 \\
2 \\
2 \\
2\end{array}$ & $\begin{array}{l}0.0 \\
0.0 \\
0.0 \\
0.0 \\
0.0\end{array}$ & $\begin{array}{l}5.400 \\
17.280 \\
30.100 \\
43.285 \\
98.034\end{array}$ & $\begin{array}{l}1 \\
2 \\
2 \\
2 \\
2\end{array}$ & $\begin{array}{l}0.0 \\
3.660 \\
4.732 \\
5.223 \\
6.063\end{array}$ \\
\hline $0.25 n$ & $\begin{array}{r}2 \\
4 \\
6 \\
8 \\
16\end{array}$ & $\begin{array}{r}5.250 \\
16.424 \\
28.247 \\
40.444 \\
92.930\end{array}$ & $\begin{array}{l}0.0 \\
0.0 \\
0.0 \\
0.0 \\
1.7\end{array}$ & $\begin{array}{l}1 \\
1 \\
1 \\
1 \\
1\end{array}$ & $\begin{array}{l}0.0 \\
3.588 \\
4.143 \\
4.905 \\
5.751\end{array}$ & $\begin{array}{r}5.250 \\
16.250 \\
27.447 \\
40.025 \\
90.340\end{array}$ & $\begin{array}{l}0.0 \\
1.1 \\
2.8 \\
1.1 \\
4.1\end{array}$ & $\begin{array}{l}1 \\
1 \\
2 \\
2 \\
2\end{array}$ & $\begin{array}{l}0.0 \\
0.0 \\
0.0 \\
0.0 \\
0.0\end{array}$ & $\begin{array}{r}5.250 \\
16.424 \\
28.247 \\
40.454 \\
94.524\end{array}$ & $\begin{array}{l}1 \\
1 \\
1 \\
2 \\
2\end{array}$ & $\begin{array}{l}0.0 \\
3.588 \\
4.143 \\
4.905 \\
5.848\end{array}$ \\
\hline $0.50 n$ & $\begin{array}{c}2 \\
4 \\
6 \\
8 \\
16 \\
\end{array}$ & $\begin{array}{r}5.000 \\
16.154 \\
27.919 \\
40.112 \\
92.431\end{array}$ & $\begin{array}{l}0.0 \\
0.0 \\
0.0 \\
0.0 \\
0.0 \\
==\end{array}$ & $\begin{array}{l}1 \\
1 \\
1 \\
1\end{array}$ & $\begin{array}{l}0.0 \\
3.504 \\
4.380 \\
4.858 \\
5.717\end{array}$ & $\begin{array}{r}5.000 \\
16.000 \\
27.000 \\
38.000 \\
86.340\end{array}$ & $\begin{array}{l}0.0 \\
1.0 \\
3.4 \\
5.6 \\
7.1\end{array}$ & $\begin{array}{l}1 \\
1 \\
1 \\
1 \\
2\end{array}$ & $\begin{array}{l}0.0 \\
0.0 \\
0.0 \\
0.0 \\
0.0\end{array}$ & $\begin{array}{r}5.000 \\
16.154 \\
27.919 \\
40.112 \\
92.431\end{array}$ & $\begin{array}{l}1 \\
1 \\
1 \\
1 \\
1\end{array}$ & $\begin{array}{l}0.0 \\
3.504 \\
4.380 \\
4.858 \\
5.717\end{array}$ \\
\hline
\end{tabular}


observe most agents drawing more than one sample of offers when they have the option of doing so we can reject the fixed-sample-size model. Finally, if we observed most of the agents drawing several samples in period 1 not all of unit size then we could check with Table 2 and see if the sample size and stop/continue decisions taken are the optimal ones listed there. However, we contend that this is not a very informative route to follow and instead offer an alternative way of interpreting the data and judging the explanatory powers of the three models.

Consider Table 3 which displays the losses in expected net value of continuing to search when the agent chooses various sample sizes given $T=4$, the BETA3 wage offer distribution, and the sampling cost function $T C(n)=$ $0.25 \mathrm{n}$. The smallest value for the opportunity cost of a sub-optimal sample size choice at date $t$ is then the difference between the maximal expected net value and the expected net value corresponding to the sample size actually chosen, assuming that an optimal search policy is followed in all remaining periods. For example, when $t=1$ the optimal vss sample size is $n_{1}^{*}=7$ and the expected net value of searching further is $\$ 7.764$. Choosing a sample size $n_{1}=2$ at this point has an opportunity cost of at least $\$ 7.764-$ $\$ 6.946=\$ 0.818$. Notice that these minimal opportunity costs are quite smal1 for sample sizes near to the optimal choice. For instance, choosing $n_{2}=3$ instead of the optimal value $n_{2}^{*}=5$ when $t=2$ generates a minimal opportunity cost of just $2.08 \%$ of the expected value of the optimal strategy. The table also shows, however, that some these minimal opportunity costs do become rather large.

In our analysis of the data we give little weight to a datum which corresponds to a small minimal opportunity cost and large weight to a datum 
TABLE 3

Losses in Expected Present Value for Sub-optimal Sample Size

BETA3 population; $T=4 ; \quad T C=\$ 0.25 n$

Sample Size

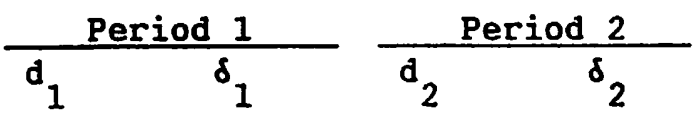

$\frac{\text { Period } 3}{d_{3}}$

\begin{tabular}{|c|c|c|c|c|c|c|}
\hline 0 & $\$ 7.764$ & 100.00 & $\$ 4.707$ & 100.00 & $\$ 1.933$ & 100.00 \\
\hline $1 \quad\left(n_{1}^{s}=n_{2}^{s}=n_{3}^{s}\right)$ & 1.528 & 19.68 & 0.968 & 21.24 & 0.188 & 9.72 \\
\hline $2\left(n_{3}^{\star}\right)$ & 0.818 & 12.88 & 0.342 & 7.27 & 0.0 & 0.0 \\
\hline 3 & 0.431 & 5.55 & 0.098 & 2.08 & 0.003 & 0.16 \\
\hline 4 & 0.205 & 2.64 & 0.009 & 0.19 & 0.084 & 4.34 \\
\hline $5\left(n_{2}^{*}\right)$ & 0.075 & 0.97 & 0.0 & 0.0 & 0.204 & 10.55 \\
\hline 6 & 0.012 & 0.15 & 0.040 & 0.85 & 0.349 & 18.05 \\
\hline $7\left(n_{1}^{*}\right)$ & 0.0 & 0.0 & 0.115 & 2.44 & 0.511 & 26.43 \\
\hline 8 & 0.026 & 0.33 & 0.215 & 4.57 & 0.687 & 35.54 \\
\hline 9 & 0.083 & 1.07 & 0.336 & 7.14 & 0.872 & 45.11 \\
\hline 10 & 0.163 & 2.10 & 0.473 & 10.05 & 1.066 & 55.15 \\
\hline 11 & 0.262 & 3.37 & 0.623 & 13.24 & 1.266 & 65.49 \\
\hline 12 & 0.377 & 4.86 & 0.782 & 16.61 & 1.470 & 76.04 \\
\hline 13 & 0.504 & 6.49 & 0.951 & 20.20 & 1.680 & 86.91 \\
\hline 14 & 0.642 & 8.27 & 1.126 & 23.92 & 1.892 & 97.87 \\
\hline 15 & 0.788 & 10.15 & 1.306 & 27.74 & 2.102 & 108.74 \\
\hline
\end{tabular}

Notes: $d_{t} \equiv \operatorname{EPV}_{t}^{*}\left(n_{t}^{*}\right)-\operatorname{EPV}_{t}^{*}\left(n_{t}\right)$.

$\delta_{t} \equiv d_{t} /\left[\operatorname{EPV}_{t}^{*}\left(n_{t}^{*}\right)\right] \cdot 100$. 
corresponding to a large minimal opportunity cost, contending (in the manner of Marschak [1968] and Simon [1955] [1959]) that the reality is that agents have computational and perceptual limitations which inhibit, or make irrational, their attaining exact solutions to difficult problems. We intend to examine the data to see what perceptual abilities need to be assumed for each of the three search models in order to make them consistent with the data. The model which requires the smallest assumed perceptive ability will be pronounced the model "closest" to the data. Of course, even this model's performance may be unsatisfactory.

\section{EXPERIMENTAL DESIGN}

Each experimental subject was presented with the 23 search problems listed in Table 1 in the sequence shown. Prior to this session each subject had participated in a separate series of (unpaid) "training" problems qualitatively similar to those listed in Table 1.

The 23 problems used in our main experimental session were carefully chosen on the basis of the experimental predictions described in the previous section. Problems 4 to 23 are paired in that they differ only in the search strategy allowed; for example, Problem 4 is paired with Problem 5, Problem 6 with Problem 7, and so on. The vSS strategy was always first in each of these pairings so as to avoid any bias, due to "learning", in favour of the vSs strategy. Problems 1,2 and 3 are a triple of problems differing only in the search strategy allowed. Again the vSs strategy is placed first.

of the 23 problems used, 7 restrict the agent to using a FSS strategy, 6 restrict him to a SEQ strategy, and the remaining 10 allow him to use a vSS strategy which, of course, admits the FSS and SEQ strategies if he wishes to use one of them. 
Denote by $\alpha_{t}^{s}$ and $\alpha_{t}^{f}$ the percentage difference in the

theoretical expected net value of the optimal vSS strategy and the SEQ and FSS strategies in period $t$, respectively; that is

$$
\alpha_{t}^{s}=100\left(E_{t}^{*}-E P V_{t}^{s}\right) / E P v_{t}^{*}
$$

and

$$
\alpha_{t}^{f}=100\left(E P v_{t}^{*}-E P v_{t}^{f}\right) / E P v_{t}^{*}
$$

The seven FSS strategy problems were selected so as to span a wide range of $\alpha_{1}^{f}$ values, from $4.5 \%$ to $26.1 \%$. The six SEQ strategy problems were similarly selected, giving $\alpha_{1}^{s}$ values ranging from $4.2 \%$ to $30.5 \%$.

Prior to the experimental sessions each subject was presented given copies of the following instructions and Figures 1 to 4 , and familiarized with them:

\section{Introduction}

The purpose of these experiments is to find out how people go about searching for prices and wages. If you want you can assume that you are a worker who may or may not decide to look for a job in a number of periods. The only characteristic of the job that you care about is the wage it pays. You will be told by the computer the number of periods in each experiment. You should try to make as much money over the entire experiment as you can. We may adjust the total monetary payoff by some fraction, but you will be advised of this before the experiment.

There are three RULES that determine how you may SEARCH in each experiment. You will be told which RULE applies in each experiment at the beginning of each experiment. The RULES are described in the experiment as follows:

RULE I applies in this experiment. You may choose to SEARCH in any period. You may only obtain ONE job offer in each period that you choose to SEARCH.

OR... 
RULE II applies in this experiment. You may choose to SEARCH in the FIRST period. You may NOT choose to SEARCH in any subsequent periods. If you choose to SEARCH in period 1 you may obtain as many job offers as you wish.

OR...

RULE III applies in this experiment. You may choose to SEARCH in any period. You may obtain any number of job offers in any period that you choose to SEARCH.

It is easiest to explain first how RULE III works: the other two RULES are then straightforward to understand.

2. Rule III

In general you have three options available in each period: you can WORK in a job, you can SEARCH for a higher paying job, or you can choose NOT to SEARCH. Which of these options is available to you in each period depends on your behavior in the previous period, as follows:

(i) if you did not WORK or SEARCH in the immediately previous period, then you may choose to SEARCH or NOT SEARCH in the current period;

(ii). if you chose to SEARCH for a job in the immediately previous period, then you may choose to WORK at the job with the highest wage offered to you, continue your SEARCH for a higher paying job, or NOT SEARCH in the current period; and

(iii) if you WORKED in the immediately previous period, then you may choose to WORK at your old job (at the same wage), SEARCH for a new job, or NOT SEARCH in the current period.

Your monetary payoff in each period depends on the net income that you earn as a result of your choice.

If you decide not to WORK in any period, you will receive a certain income. The exact value of this non-work income will be constant for all of the periods in each game, and will be told to you by the computer at the outset of the game. You will receive this income whether you choose to SEARCH or NOT SEARCH.

If you decide to wORK in your old job you will receive your old wage. If you engaged in SEARCH in the previous period for a new job and now decide to accept the best offer received, you will receive the new wage that was offered. NOTE THAT YOU MAY ONLY ACCEPT WAGE OFFERS FROM THE IMMEDIATELY PREVIOUS PERIOD. You are not allowed to "recall" wage offers from periods earlier than the immediately previous period. 
If you decide to SEARCH in any period, you will be asked by the computer to specify how many wage offers you want to receive. Each wage offer that you receive will cost you a certain monetary amount. The cost of SEARCH is described later in these instructions. The number of offers that you select must be positive and it must be an integer (i.e., you cannot request -3 of fers or $11 / 2$ offers). The computer will then tell you the cost of the number of of fers that you request.

\section{RULE I}

In this case you are still allowed to SEARCH in any period, but you only purchase one job of fer in each period if you decide to SEARCH in that period. You may SEARCH in as many periods as you wish.

In all other respects RULE I is the same as RULE III.

\section{RULE II}

In this case you are only allowed to SEARCH In the first period of the experiment. You are not allowed to SEARCH in any subsequent periods for that experiment. If you do SEARCH In period 1 you may choose any number of job offers.

In all other respects RULE II is the same as RULE III.

\section{DISTRIBUTION OF WAGES}

When you SEARCH for a new wage the computer will draw your sample from a particular distribution of wages. One example of such a distribution is the triangular distribution shown below:

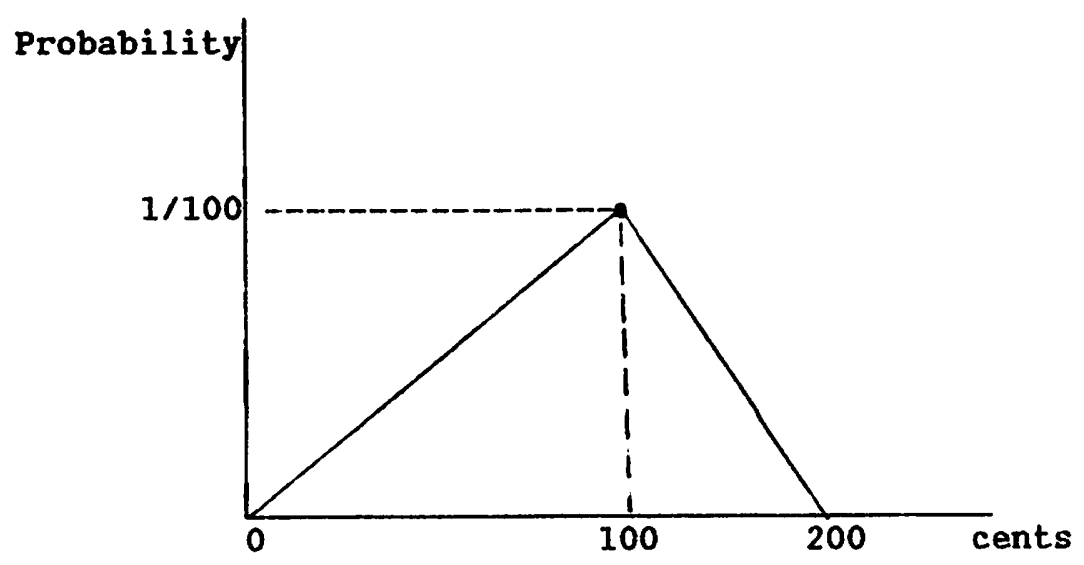

This graph indicates that the probability of getting a wage of 100 cents is greatest (at $1 / 100$ ). The probability of getting a wage offered to you which is either above or below 100 cents falls off symmetrically until the probability of actually getting a 0 or 200 cent wage offer is zero. If you were to draw a large sample of wage offers from this distribution and calculate the average wage received in that sample, it would tend to be 100 cents. The average wage of the distribution is 100 cents. 
Before each experiment you will be told which distribution applies, and given a graph such as the one above. Note that the distribution may not be the triangular distribution presented as an example above. In fact, it will be one of the four distributions graphed in the next few pages. You will be told precisely which distribution applies for each experiment at the beginning of each experiment.

\section{COST OF SEARCH}

The cost to you of SEARCH is determined in one of two ways:

a constant cost for each job of fer that you receive (e.g., $\$ 0.50$ per offer times 8 offers implies a total cost of $\$ 4.00)$; or

a non-constant cost for each job offer, as indicated on the schedules given below.

You will be told at the beginning of each experiment which of these two types of cost applies. If it is the first type you will be told the constant cost by the computer at the beginning of each experiment. If it is the second type you should consult the cost schedule that the computer indicates.

The non-constant SEARCH Cost Schedule referred to in the instructions is presented in Table A5 in Appendix A.

Each subject first participated in an unpaid session of fourteen training problems. These are presented in Table A6 in Appendix A and were designed to introduce each subject to all of the qualitiative features of the search problems to be encountered in a subsequent paid session. Each subject knew that the unpaid session provided him with experience for the later paid session. At the end of his training session each subject was privately given a printout listing his behaviour and its outcomes. The paid session was scheduled several days after each training session, with each session grouped together of minimise intra-session communication between subjects. 


\section{HYPOTHESES AND RESULTS}

It is convenient to arrange the evaluation of our experimental results around three groups of questions: is the VSS strategy preferred to the SEQ and FSS strategies?; does the freedom to follow a vSS strategy pay of $f$ in extra income?; and do the subjects behave in the theoretically optimal manner?

\section{A. Is the VSS strategy preferred?}

The VSS strategy is clearly theoretically superior to either of the SEQ or FSS strategies. Moreover, we have designed paired comparisons of search problems to try to make this superiority perceptible to our subjects. Did they, in fact, make search choices in the vSS problems that differed noticeably from choices made in the paired SEQ or FSS problems?

Consider the six paired VSS-SEQ problems. Pooling over all possible periods in which subjects might search (specifically, we exclude the final period of each problem) provides us with 20 observations per subject, or 600 observations over all subjects. The average vSS sample size (0.917) is significantly larger than the average SEQ sample size $(0.352)$. We reject with virtual certainty (critical probability less than 0.00005 ) the hypothesis that these distributions are the same using a two-sided non-parametric Kolmogorov-Smirnov test (see Conover [1980; p. 368-373]).

Now consider the six paired vSS-FSS problems. By choosing not to search in any period other than the first, a subject could mimic a FSS path in any vSS problem. Using a Kolmogorov-Smirnov test, we can reject with virtual certainty the null hypothesis that subjects in fact did this. 
A subsidiary issue is whether or not the observed sample sizes in period 1 of the VSS and FSS problems are identical. In theory, given our parameters, they should both equal 1.333 (see Table 1). However, we observe that the period 1 VSS and FSS sample distributions are indeed significantly different: the average VSS sample size is 1.450 whereas the average FSS sample size is 1.811 . A critical probability of less than 0.00005 is required of a Kolmogorov-Smirnov test in order to accept the null hypothesis that these two distributions are identical.

We conclude that the evidence shows that subjects preferred not to employ the restrictive FSS and SEQ strategies in the paired vSS problems.

\section{B. Does the USS strategy pay off?}

We now turn to see if the theoretical expected net income dominance of the VSS strategy over the SEQ and FSS strategies was realised. Although we have already concluded that our subjects did not constrain themselves to FSS or SEQ strategies in the VSS problems, there is no assurance from that result that the extra freedom of the vSs strategies actually helped them earn more money .

Consider the six paired VSS-SEQ problems again. The subjects' average income for these vSS problems was $\$ 12.772$ compared to only $\$ 11.204$ for the SBQ problems. Although more income was earned on average in the vSs problems, it is not significantly more on the basis of a Kolmogorov-Smirnov test (a critical probability of 0.26 is required to reject the null hypothesis that the sample distributions are the same). 1

Now consider the six paired VSS-FSS problems. Again the vSS average income of $\$ 11.887$ is higher than the average income $(\$ 11.162)$ of the more restrictive search rule, but not significantly higher (critical probability 
of 0.32 with a Kolmogorov-Smirnov test).

We conclude that the evidence shows that subjects did not exploit the flexibility of the vSS strategy to earn significantly more money on average in VSS problems than in comparable FSS or SEQ problems. This result is noteworthy because we were careful to select paired problems for which the vSs strategy did allow subjects to earn (what we thought was) significantly higher income (recall the final two columns of Table 1). On the other hand, we did "sequence" the VSS-SEQ and VSS-FSS pairs so as to "disadvantage" the VSS problem. Future experiments can determine if this sequencing effect explains our results or if the subjects were simply unable to make more effective use of the flexibility of the vSS strategy.

\section{Do the subjects behave optimally?}

We now consider how close the subjects came to the theoretically optimal search strategy for each problem. How serious were the errors that were observed? We find it meaningful to pose this question in the following form: how poor do our subjects' perceptual abilities need to be in order to reconcile the observed and theoretically predicted behaviors?

One might respond that any deviations of expected income from the predicted value, however small, should lead us to reject that theory. We regard this inferential position as impractical, implying a scientific nihilism that is not widespread. But an important issue now arises: what is the perceptive threshold of experimental subjects? If it is deemed to be a penny (per observable action) then any observed decisions that result in the loss of less than a penny to the subject are not perceptually significant deviations from theory using this proposed metric. We do not want to be 
dogmatic on the question of the value or the correct manner of measuring "the" perceptive threshold, although there is some experimental literature on this issue. $^{2}$ Rather we present a mapping from various values for this perceptive threshold level to the set of inferences as to the significance of subject behavior that is "irrational" in the context of the search models considered here.

Consider the possible errors that a subject might make in a FSS problem. The only choice open to the subject is the sample size in the first period. Any sub-optimal value for this sample implies a loss in expected income over the horizon of the problem. Table 4 provides measures of the "significance" of subject misbehavior in the FSS experiments. These measures are conditional on assumed values for the perceptive threshold of subjects. We provide a range of threshold values between 1 and 25 cents (for foregone expected income) and 1 and 25 percent (for percent foregone expected income).

In Table 4 we list the results of applying a non-parametric sign test of the statistical significance of observing the indicated percentage of "failures" in the indicated number of "trials" conditional on a given threshold. A failure occurs when the observed variable exceeds the given threshold value; a success is any outcome between zero and that threshold value. The specific test procedure used is described in Conover [1980; $p$. $96 \mathrm{ff}$.$] and DeGroot [1975; p. 482]. Our test is one-tailed, with the null$ hypothesis being that the probability of a failure on any trial is less than or equal to one-half. The alternative hypothesis is that the probability of a failure on any trial is greater than one-half. We report the critical (minimal) probability level required to reject the null hypothesis. A low critical probability value is "good" for the theory since it indicates that the observed failure rate of the theory was probably a chance event. 
TABLE 4

Binomial Test Results: FSS Sampling Errors

\begin{tabular}{|c|c|c|c|c|}
\hline \multirow{2}{*}{$\begin{array}{l}\text { Perceptive } \\
\text { Threshold } \\
\text { in Cents } \\
\text { or Percent } \\
=============\end{array}$} & & $\begin{array}{l}\text { regone } \\
\text { pected } \\
\text { come }\end{array}$ & $\begin{array}{r}\text { Perce } \\
\text { E }\end{array}$ & $\begin{array}{l}\text { ent Foregone } \\
\text { Expected } \\
\text { Income }\end{array}$ \\
\hline & $\begin{array}{c}\% \text { Fail } \\
\text { \% }\end{array}$ & $\begin{array}{l}\text { Probability } \\
====-==0==0=0\end{array}$ & \% Fail & Probability \\
\hline 1 & 47 & 0.251 & 47 & 0.251 \\
\hline 2 & 47 & 0.251 & 38 & 0.001 \\
\hline 3 & 47 & 0.251 & 38 & 0.001 \\
\hline 4 & 47 & 0.251 & 26 & 0.000 \\
\hline 5 & 47 & 0.251 & 17 & 0.000 \\
\hline 6 & 47 & 0.251 & 9 & 0.000 \\
\hline 7 & 47 & 0.251 & 9 & 0.000 \\
\hline 8 & 47 & 0.251 & 9 & 0.000 \\
\hline 9 & 47 & 0.251 & 9 & 0.000 \\
\hline 10 & 47 & 0.251 & 8 & 0.000 \\
\hline 11 & 47 & 0.251 & 8 & 0.000 \\
\hline 12 & 47 & 0.251 & 8 & 0.000 \\
\hline 13 & 47 & 0.251 & 8 & 0.000 \\
\hline 14 & 47 & 0.251 & 8 & 0.000 \\
\hline 15 & 47 & 0.251 & 8 & 0.000 \\
\hline 16 & 47 & 0.251 & 8 & 0.000 \\
\hline 17 & 47 & 0.251 & 2 & 0.000 \\
\hline 18 & 47 & 0.251 & 2 & 0.000 \\
\hline 19 & 35 & 0.000 & 2 & 0.000 \\
\hline 20 & 35 & 0.000 & 2 & 0.000 \\
\hline 21 & 35 & 0.000 & 2 & 0.000 \\
\hline 22 & 35 & 0.000 & 2 & 0.000 \\
\hline 23 & 35 & 0.000 & 2 & 0.000 \\
\hline 24 & 35 & 0.000 & 2 & 0.000 \\
\hline 25 & 35 & 0.000 & 2 & 0.000 \\
\hline
\end{tabular}


The results in Table 4 focus attention on the "metric of evaluation" of subject behaviour. If one chooses foregone expected income as that metric, then the critical probability of acceptance for the theoretical predictions only drops below 0.251 for perceptive thresholds of $\$ 0.19$ or more. ${ }^{3}$ Thus, if one were to insist that these subjects behaved in accordance with theory in this case, one would need to be tolerant of perceptive indifference to errors worth 18 cents or less. On the other hand, the percent foregone income level required to accept the theory at conventional significance levels (greater than 0.001 ) is only 2 percent.

Table 4 also emphasizes the point that there almost always exist perceptive threshold levels at which the theoretical predictions are (perceptually) significantly different from observed behavior. The issue is whether or not those threshold levels strike one as plausible or not.

Consider now the SEQ problems. In this case the only possible decision errors concern the "work or search" choice in each period. We calculate the foregone expected income from a sub-optimal SEQ decision in period $t$ assuming that the subject returns to the righteous path of optimal search in period $t+1$ and on. We find that only $8 \%$ of the 600 decisions observed involved an expected income loss greater than 1 cent or more than 1 percent of expected income (see Table A7 in Appendix A). On the basis of our sign test (as in Table 4) these were almost certainly chance events. Our subjects were simply superb SEQ searchers.

Finally, consider the VSS problems. We decompose the cost of errors in these problems into "Decision errors" of the "work or search" variety, and "Sampling errors" concerning the choice of sample size given that the subject has (rightly or wrongly) comnitted himself to search in a period. We 
have 55 observations per subject of possible vss decision errors (or 1650 over all 30 subjects) and a variable number of observations per subject of possible vSS Sampling errors (the number depending on how many periods the subject chose to search; over all subjects there were 450 such observations). Just on $20 \%$ of the Decision errors and $40 \%$ of the Sampling errors involved perceptive thresholds of at least one cent or at least one percent. Each of these failure rates for the theory can be dismissed as almost certainly chance events, given the large number of observations (see Tables A8 and A9 in Appendix A).

We conclude that our subjects only deviated noticeably from the optimal search path when faced with FSS problems. Moreover, even those deviations were small in terms of the percentage of expected income foregone.

\section{CONCLUDING REMARKS}

We have examined three alternative search strategies. We find that experimental subjects do employ the least restrictive, and thus most (potentially) remunerative, strategy when given the opportunity to do so. The subjects also managed to earn more money on average when using the least restrictive search strategy, although not significantly more.

The subjects are able to pursue the optimal SEQ and vSs strategy with perceptive thresholds that are, per decision, less than one cent and less than one percent of the optimal expected income. They do noticeably less well when faced with the FSS strategy. A perceptive threshold (per sampling decision) of over 18 cents per decision would be required before one could say that our subjects behaved consistently with the theoretical predictions in this case. We emphasize that our experimental design was very carefully chosen in order to make the cost of sub-optimal decisions salient to the subjects. One 
might object that it is therefore no wonder that our subjects did so well overall, since they were "properly motivated" to do so. Such a criticism merely agrees with the motivational postulate of the models and points out that we have constructed a controlled experimental microeconomy in the sense of Smith [1982]. To study subject behavior in an uncontrolled microeconomy in which decision errors are not salient would be uninformative. 
FOOTNOTES

1. A non-parametric test, such as we use, is particularly appropriate here. The skewness of the VSS and SEQ distributions are 1.131 and 1.256, respectively; the reference skewness for a Gaussian distribution is only 0.183 . In this context, we should note that all of the distributions we observe (i.e., the sample size and income distributions for each search rule) are severely positively skewed. Moreover, they are generally leptokurtic relative to a reference Gaussian distribution. Parametric statistical procedures should be used with caution on such samples, and can lead to very different conclusions (e.g., a t-test on the VSS-SEQ paired incomes would lead one to conclude that more income was earned in the vss problems with critical

probability 0.0016).

2. See Green and Swets [1974] on signal-detection experiments, Myers, Fort, Katz and Suydam [1963] on binary choice experiments, and Siegel [1961] on Bernoulli trials experiments, for example. Heiner [1985] and winter [1982] review some of this literature for economists. Decision theorists and practitioners have long been aware of related "flat maxima" problems: see Von Winterfeldt and Edwards [1986; Ch. 11]. In experimental economics there is one recent study that bears on the perceptive threshold question: Smith and williams [1983] vary the level of commissions in a double auction context.

3. Why is there such a sharp drop from a failure rate of $47 \%$ to a failure rate of $35 \%$ as we vary the perceptive threshold only by one penny ( $f$ rom $\$ 0.18$ to $\$ 0.19)$ ? This is due to 22 of the 30 subjects making one specific sub-optimal decision. In problem 21 the optimal sample size is 1 ; these 22 subjects chose a sample of 2 , foregoing an expected income of \$0.185. This particular choice also accounts for most of the decline in the failure rate for the percent foregone expected income metric as we vary the threshold from $3 \%$ to $4 \%$ (this error involves a $3.14 \%$ loss). 


\section{REFERENCES}

Benhabib, Jess, and Bull, Clive, "Job Search: The Choice of Intensity," Journal of Political Economy, v. 91, 1983, Pp. 747-764.

Berg, Joyce E., Daley, Lane A., Dickhaut, John W., and $0^{\prime}$ Brien, John R., "Controlling Preferences for Lotteries on Units of Experimental

Exchange," Quarterly Journal of Economics, v. 101, May 1986, pp. 281-306.

Braunstein, Yale M., and Schotter, Andrew, "Labor Market Search: An Experimental Study," Economic Inquiry, v. 20, January 1982, pp. 133-144.

Conover, W. J., Practical Nonparametric Statistics (Second Edition; New York: Wiley, 1980).

Connolly, Terry, and Gilani, Nareed, "Information Search in Judgement Tasks: A Regression Model and Some Preliminary Findings," Organizational Behavior and Human Performance, v. 30, 1982, pp. 330-350.

Connolly, Terry, and Serre, Patrice, "Information Search in Judgement Tasks: The Effects of Unequal Cue Validity and Cost," Organizational Behavior and Human Performance, v. 34, 1984, pp. 387-401.

Cox, James C., and Oaxaca, Ronald L., "Laboratory Experiments With a Finite Horizon Job Search Model," Discussion Paper No. 86-11, Department of Economics, University of Arizona, 1986.

DeGroot, M.H., Probability and Statistics (Reading: Addison-Wesley, 1975).

Gal, Shmuel, Landsberger, Michael, and Levykson, Benny, "A Compound Strategy for Search in the Labour Market," International Economic Review, v. 22, 1981, pp. 597-608.

Green, D.M., and Swets, J.A., Signal Detection Theory and Psychophysics (New York: Robert Kriegur, 1974).

Green, Paul E., Halbert, Michael H., and Minas, J. Sayer, "An Experiment in Information Buying," Journal of Advertising Research, v. 4, 1964, pp. 17-23.

Heiner, R.A., "Uncertainty, Signal-Detection Experiments, and Modeling Behavior", in R.N. Lanlois (eds.), Economics As A Process (New York: Cambridge University Press, 1985).

Hershman, Ramon L., and Levine, J. R., "Deviations from Optimum InformationPurchase Strategies in Human Decision-Making," Organizational Behavior and Human Performance, v. 5, 1970, pp. 313-329.

Lippman, Steven A., and McCal1, John J., "The Economics of Job Search: A Survey," Economic Inquiry, v. 14, 1976, Part I pp. 155-190, Part II pp. 347-369. 
Marschak, Jacob, "Economics of Inquiring, Communicating, Deciding", American Economic Review (Papers and Proceedings), v. 58, May 1968, pp. Morgan, Peter, "Search and Optimal Sample Sizes," Review of Economic Studies,
v. 50, 1983, pp. 659-675. Morgan, Peter, and Manning, Richard, "Optimal Search," Econometrica, v. 53,
1985.

Myers, J.L., Fort, J.G., Katz, L., and Suydam, M.M., "Differential Monetary Gains and Losses and Event Probability in a Two-Choice Situation", Journal of Experimental Psychology, v. 66, 1963, pp. 521-22.

Rapoport, Amnon, and Tversky, Amos, "Choice Behavior in an Optional stopping Task,"̈ Organizational Behavior and Human Performance, v. 5, 1970, pp.

Rapoport, Amnon, and Wallsten, T. S., "Individual Decision Behavior," Annual Review of Psychology, v. 23, 1972, pp. 131-176.

Schotter, Andrew, and Braunstein, Yale M., "Economic Search: An Experimental Study," Economic Inquiry, v. 19, January 1981, pp. 1-25.

Siegel, S., "Decision Making and Learning Under Varying Conditions of Reinforcement", Annals of the New York Academy of Science, v. 89, 1961,
pp. 766-783.

Simon, Herbert A., "A Behavioral Model of Rational Choice", Quarterly Journal of Economics, v. 69, February 1955, pp. 99-118.

Simon, Herbert A., "Theories of Decision-Making in Economics and Behavioral Science", American Economic Review, v. 49, June 1959, pp.
253-283.

Smith, Vernon L., "Microeconomic Systems As An Experimental Science", American Economic Review, v. 72, December 1982, pp. 923-955.

Smith, V.L., and Williams, A.W., "An Experimental Comparison of Alternative Rules for Competitive Market Exchange", in R. Engelbrecht-Wiggans, $M$. Shubik, and R.M. Start (eds.), Auctions, Bidding, and Contracting: Uses and Theory (New York: New York University Press, 1983). Stigler, George J., "The Economics of Information," Journal of Political
Economy, v. 69, June 1961, pp. 213-225.

Von Winterfeldt, Detlof, and Edwards, Ward, "Costs and Payoffs in Perceptual Research," Psychological Bulletin, v. 91, 1982, pp. 609-622.

Von Winterfeldt, Detlof, and Edwards, Ward, Decision Analysis and Behavioral Research (Cambridge: Cambridge University Press, 1986). 
Wendt, D., "Value of Information for Decisions," Journal of Mathematical Psychology, v. 6, 1969, pp. 430-433.

Winter, S.G., "Binary Choice and the Supply of Memory", Journal of Economic Behavior and Organization, v. 3, 1982, pp. 277-321. 
TABLE AI

Theoretical Predictions for Alternative Search Strategies: BETA2 Population

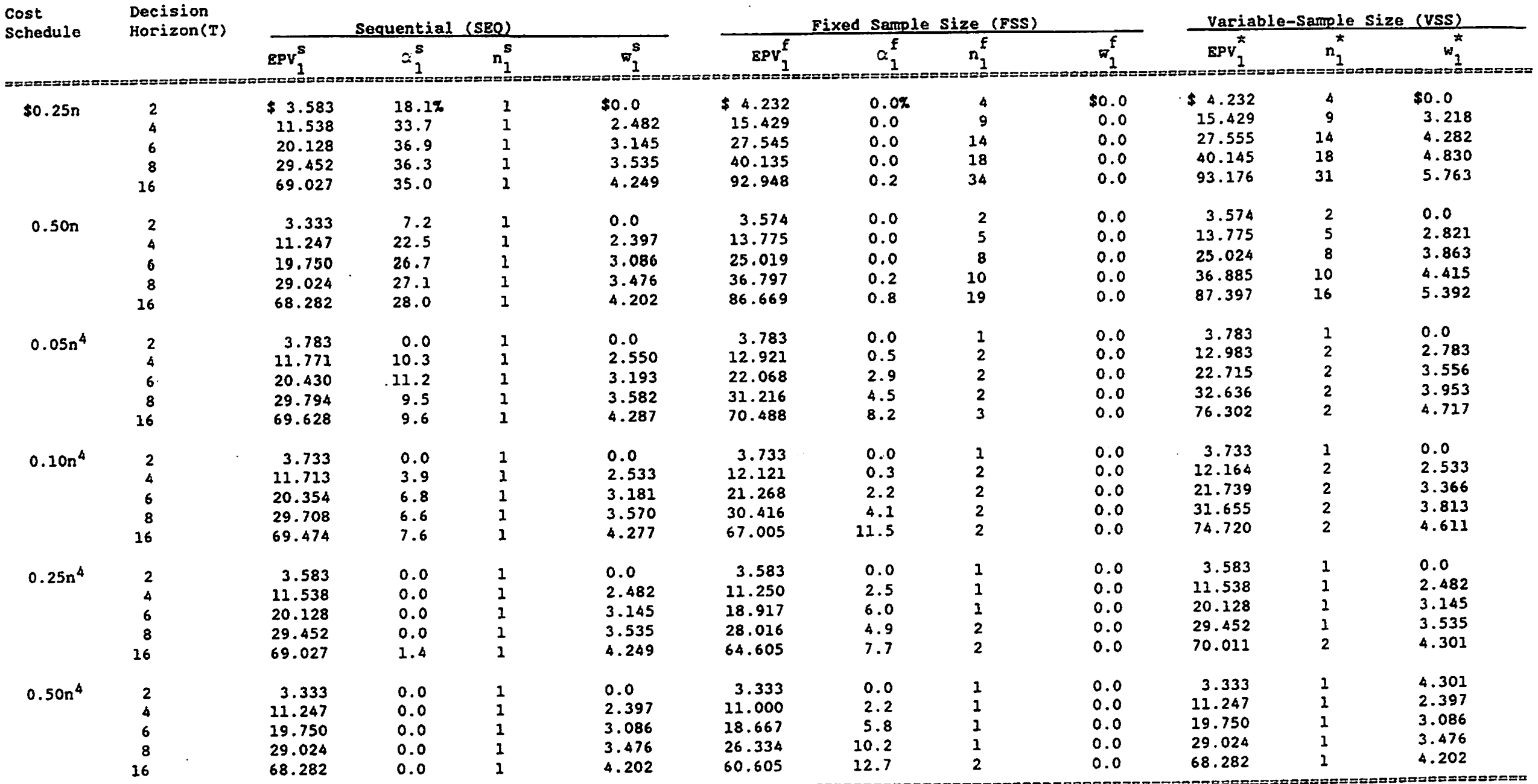


TABLE A2

Theoretical Predictions for Alternative Search Strategies: BETA3 Population

\begin{tabular}{|c|c|c|c|c|c|c|c|c|c|c|c|c|}
\hline \multirow[t]{2}{*}{$\begin{array}{l}\text { Cost } \\
\text { Schedule }\end{array}$} & \multirow[t]{2}{*}{$\begin{array}{l}\text { Decision } \\
\text { Horizon(T) }\end{array}$} & \multicolumn{4}{|c|}{ Sequential (SEO) } & \multicolumn{4}{|c|}{ Fixed Sample size (ESS) } & \multicolumn{3}{|c|}{ Variable-sample size (VSS) } \\
\hline & & 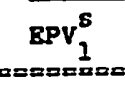 & $\begin{array}{l}\alpha^{5} \\
1 \\
=\infty=0\end{array}$ & $n_{1}^{8}$ & $\bar{w}_{1}^{-5}$ & $\begin{array}{l}\mathrm{BPV}_{1}^{\mathrm{f}} \\
\mathrm{I}====\end{array}$ & $\alpha_{1}^{f}$ & $\begin{array}{c}f \\
n_{1}\end{array}$ & $\nabla_{1}^{f}$ & $\operatorname{EPV}_{1}^{\star}$ & $n_{1}^{\star}$ & $\begin{array}{c}\bar{w}_{1}^{*} \\
=0==0\end{array}$ \\
\hline \multirow[t]{4}{*}{$\$ 0.25 n$} & $\begin{array}{l}2 \\
4\end{array}$ & $\begin{array}{l}1.744 \\
5.951\end{array}$ & $\begin{array}{l}10.8 x \\
30.5\end{array}$ & $\begin{array}{l}1 \\
1\end{array}$ & $\begin{array}{l}0.0 \\
1.246\end{array}$ & $\begin{array}{r}\$ 1.933 \\
7.764\end{array}$ & $\begin{array}{l}0.0 \% \\
0.0\end{array}$ & $\begin{array}{l}2 \\
7\end{array}$ & $\begin{array}{l}\$ 0.0 \\
0.0\end{array}$ & $\begin{array}{r}\$ 1.933 \\
7.764\end{array}$ & $\begin{array}{l}2 \\
7\end{array}$ & $\begin{array}{l}\$ 0.0 \\
1.569\end{array}$ \\
\hline & 6 & 10.695 & 34.7 & 1 & 1.660 & 14.337 & 0.4 & 11 & 0.0 & 14.402 & 10 & 2.198 \\
\hline & 8 & 15.507 & 37.9 & 1 & 1.871 & 21.286 & 0.5 & 14 & 0.0 & 21.389 & 13 & 2.554 \\
\hline & 26 & 37.417 & 39.3 & 1 & 2.291 & 51.311 & 1.6 & 30 & 0.0 & 52.113 & 25 & 3.195 \\
\hline \multirow[t]{5}{*}{$\$ 0.50 \mathrm{n}$} & 2 & 1.494 & 0.0 & 1 & 0.0 & 1.494 & 0.0 & 1 & 0.0 & 1.494 & 1 & 0.0 \\
\hline & 4 & 5.627 & 16.6 & 1 & 1.163 & 6.547 & 0.2 & 4 & 0.0 & 6.562 & 3 & 1.289 \\
\hline & 6 & 20.343 & 20.1 & 1 & 1.591 & 12.418 & 0.02 & 6 & 0.0 & 12.421 & 6 & 1.884 \\
\hline & 8 & 25.153 & 25.0 & 1 & 1.821 & 28.722 & 1.2 & 8 & 0.0 & 18.941 & 7 & 2.228 \\
\hline & 16 & 36.504 & 27.2 & 1 & 2.233 & 46.132 & 0.7 & 15 & 0.0 & 46.441 & 12 & 2.862 \\
\hline \multirow[t]{5}{*}{$\$ 0.05 n^{4}$} & 2 & 1.944 & 0.0 & 1 & 0.0 & 1.944 & 0.0 & 1 & 0.0 & 1.944 & 1 & 0.0 \\
\hline & 4 & 6.210 & 6.1 & 1 & 1.313 & 6.499 & 1.4 & 2 & 0.0 & 6.591 & 2 & 1.355 \\
\hline & 6 & 10.976 & 6.8 & 1 & 1.716 & 11.364 & 3.2 & 1 & 0.0 & 11.725 & 2 & 1.831 \\
\hline & 8 & 15.791 & 7.7 & 1 & 1.912 & 26.230 & 4.8 & 2 & 0.0 & 17.008 & 2 & 2.042 \\
\hline & 16 & 38.169 & 10.6 & 1 & 2.339 & 36.148 & 16.8 & 3 & 0.0 & 42.233 & 2 & 2.600 \\
\hline \multirow{5}{*}{$\$ 0.10 n^{4}$} & 2 & 1.894 & 0.0 & 1 & 0.0 & 1.894 & 0.0 & 1 & 0.0 & 1.894 & 1 & 0.0 \\
\hline & 4 & 6.145 & 0.0 & $i$ & 1.296 & 5.883 & 4.5 & 1 & 0.0 & 6.245 & 1 & 1.296 \\
\hline & 6 & 10.906 & 0.0 & 1 & 1.702 & 10.564 & 3.2 & 2 & 0.0 & 10.906 & 1 & 1.702 \\
\hline & 8 & 15.720 & 1.7 & 1 & 1.902 & 15.430 & 3.6 & 2 & 0.0 & 15.987 & 2 & 1.918 \\
\hline & 16 & 37.979 & 6.2 & 1 & 2.327 & 34.893 & 15.6 & 2 & 0.0 & 40.329 & 2 & 2.473 \\
\hline \multirow[t]{5}{*}{$\$ 0.25 n^{4}$} & 2 & 1.744 & 0.0 & 1 & 0.0 & 1.744 & 0.0 & 1 & 0.0 & 1.744 & 1 & 0.0 \\
\hline & 4 & 5.951 & 0.0 & 1 & 1.246 & 5.733 & 3.7 & $I$ & 0.0 & 5.951 & 1 & 1.246 \\
\hline & 6 & 10.695 & 0.0 & 1 & 1.660 & 9.722 & 10.0 & 1 & 0.0 & 10.695 & 1 & 1.660 \\
\hline & 8 & 15.507 & 0.0 & 1 & 1.871 & 13.711 & 13.1 & 1 & 0.0 & 15.507 & 1 & 1.871 \\
\hline & 16 & 37.417 & 0.0 & 1 & 2.291 & 32.493 & 13.2 & 2 & 0.0 & 37.417 & 1 & 2.291 \\
\hline \multirow[t]{4}{*}{$\$ 0.50 n^{4}$} & $\begin{array}{l}2 \\
4\end{array}$ & $\begin{array}{l}1.494 \\
5.627\end{array}$ & $\begin{array}{l}0.0 \\
0.0\end{array}$ & $\begin{array}{l}1 \\
1\end{array}$ & $\begin{array}{l}0.0 \\
1.163\end{array}$ & $\begin{array}{l}1.494 \\
5.483\end{array}$ & $\begin{array}{l}0.0 \\
2.6\end{array}$ & $\begin{array}{l}1 \\
1\end{array}$ & $\begin{array}{l}0.0 \\
0.0\end{array}$ & $\begin{array}{l}1.494 \\
5.627\end{array}$ & $\begin{array}{l}1 \\
1\end{array}$ & $\begin{array}{l}0.0 \\
1.163\end{array}$ \\
\hline & 6 & 10.343 & 0.0 & 1 & 1.591 & 9.472 & 9.2 & 1 & 0.0 & 10.343 & 1 & 1.591 \\
\hline & 8 & 15.153 & 0.0 & 1 & 1.821 & 13.461 & 12.6 & 1 & 0.0 & 15.153 & 1 & 1.821 \\
\hline & 16 & 36.504 & 0.0 & 1 & 2.233 & 29.416 & 24.1 & 1 & 0.0 & 36.504 & 1 & 2.233 \\
\hline
\end{tabular}


TABLE A3

Theoretical Predictions for Alternative Search Strategies: BRTA\& population

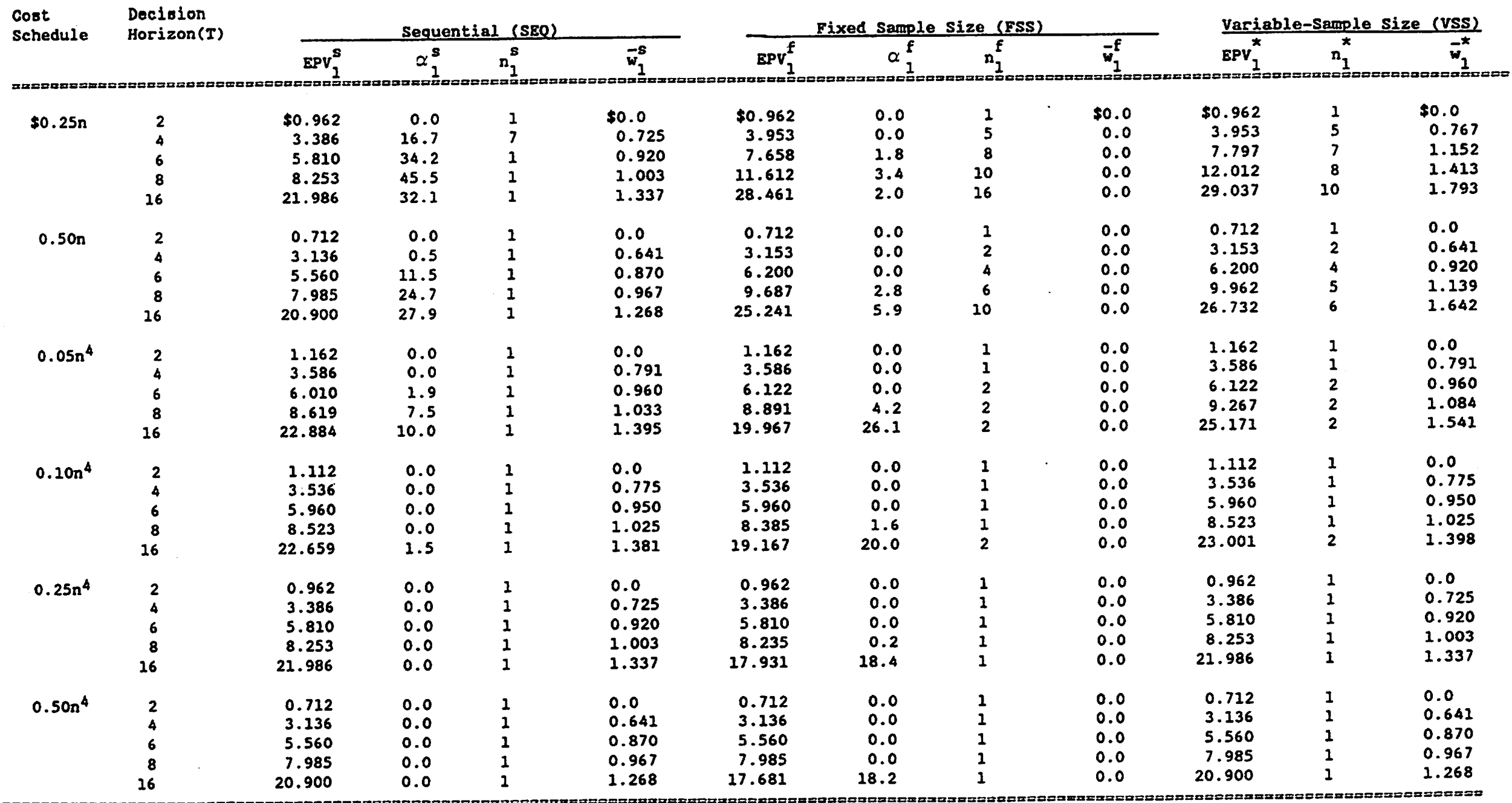


TABLE A4

Theoretical Predictions for Research Experiments

(a) Variable Sample Size Problems

Problem Period $t \quad$ EPV $_{t}^{*} \quad n_{t}^{*} \quad w_{t}^{*}$

1

8

10

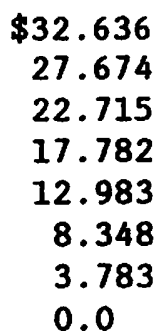

10.695

8.302

5.951

3.739

1.744

0.0

5.289

0.0

7.764

4.707

1.933

0.0

25.171

23.109

21.053

19.008

16.977

14.970

13.000

11.088

9.267

2
2
2
2
2
2
1
0

$\$ 3.953$

3.786

3.556

3.246

2.783

1.892

0.0

1.660

1.488

1.246

0.872

0.0

1

--

0.0

$2 \quad 0.0$

$\begin{array}{ll}7 & 1.569 \\ 5 & 0.066 \\ 2 & 0.0 \\ 0 & --\end{array}$

1.541

1.504

1.462

1.415

1.361

1.300

1.232

1.158

1.084 


\begin{tabular}{|c|c|c|c|c|}
\hline & 10 & 7.585 & 2 & 1.020 \\
\hline & 11 & 6.122 & 2 & 0.960 \\
\hline & 12 & 4.798 & 1 & 0.897 \\
\hline & 13 & 3.586 & 1 & 0.791 \\
\hline & 14 & 2.374 & 1 & 0.581 \\
\hline & 15 & 1.162 & 1 & 0.0 \\
\hline & 16 & 0.0 & 0 & -- \\
\hline 12 & 1 & 6.562 & 3 & 1.289 \\
\hline & 2 & 3.866 & 2 & 0.747 \\
\hline & 3 & 1.494 & 1 & 0.0 \\
\hline & 4 & 0.0 & 0 & -- \\
\hline 14 & 1 & 15.507 & 1 & 1.871 \\
\hline & 2 & 13.099 & 1 & 1.782 \\
\hline & 3 & 10.695 & 1 & 1.660 \\
\hline & 4 & 8.302 & 1 & 1.488 \\
\hline & 5 & 5.951 & 1 & 1.246 \\
\hline & 6 & 3.739 & 1 & 0.872 \\
\hline & 7 & 1.744 & 1 & 0.0 \\
\hline & 8 & 0.0 & 0 & -- \\
\hline 16 & 1 & 18.085 & 2 & 3.926 \\
\hline & 2 & 11.779 & 2 & 2.745 \\
\hline & 3 & 5.489 & 2 & 0.0 \\
\hline & 4 & 0.0 & 0 & -- \\
\hline 18 & 1 & 10.343 & 1 & 1.591 \\
\hline & 2 & 7.957 & $I$ & 1.407 \\
\hline & 3 & 5.627 & 1 & 1.163 \\
\hline & 4 & 3.489 & 1 & 0.747 \\
\hline & 5 & 1.494 & 1 & 0.0 \\
\hline & 6 & 0.0 & 0 & -- \\
\hline 20 & 1 & 6.145 & 1 & 1.296 \\
\hline & 2 & 3.889 & 1 & 0.947 \\
\hline & 3 & 1.894 & 1 & 0.0 \\
\hline & 4 & 0.0 & 0 & -- \\
\hline 22 & 1 & 17.280 & 2 & 3.660 \\
\hline & 2 & 10.979 & 2 & 2.700 \\
\hline & 3 & 5.400 & 1 & 0.0 \\
\hline & 4 & 0.0 & 0 & - \\
\hline
\end{tabular}


(b) Fixed Sample Size Problems

\begin{tabular}{ccrcc} 
Problen & Period $t$ & $\operatorname{EPV}_{1}^{f}$ & $\mathbf{n}_{1}^{f}$ & $\begin{array}{c}\mathbf{f} \\
\mathbf{w}_{1}\end{array}$ \\
\hline 5 & 1 & 31.216 & 2 & 0.0 \\
11 & 1 & 9.722 & 1 & 0.0 \\
15 & 1 & 19.967 & 2 & 0.0 \\
19 & 1 & 13.711 & 1 & 0.0 \\
21 & 1 & 9.472 & 1 & 0.0 \\
\hline & 1 & 5.883 & 1 & 0.0
\end{tabular}

- (c) Sequential Problems

$\begin{array}{lcccc}\text { Problem } & \text { Period } t & { }^{s} & n^{s} & w^{t} \\ & & t & t\end{array}$

3

$\begin{array}{lll}29.794 & 1 & 3.582 \\ 25.074 & 1 & 3.405 \\ 24.430 & 1 & 3.193 \\ 15.965 & 1 & 2.943 \\ 11.771 & 1 & 2.550 \\ 7.650 & 1 & 1.892 \\ 3.783 & 1 & 0.0 \\ 0.0 & 0 & -- \\ & & \\ 5.000 & 1 & 0.0 \\ 0.0 & 0 & - \\ & & \\ 5.951 & 1 & 1.246 \\ 3.739 & 1 & 0.872 \\ 1.744 & 1 & 0.0 \\ 0.0 & 0 & -\end{array}$

13

16.640

3.656

$\begin{array}{lll}10.967 & 1 & 2.725\end{array}$

$5.450 \quad 1$

0.0

0.0

$-$

17

3.656

$10.967 \quad 1$

2.725

$5.450 \quad 0$

0.0

23

0.0

0

$-$

$\begin{array}{ccc}16.586 & 1 & 3.639 \\ 10.917 & 1 & 2.700 \\ 5.400 & 1 & 0.0 \\ 0.0 & 0 & -\end{array}$


TABLE A5

Non-Constant SEARCH Cost Schedules

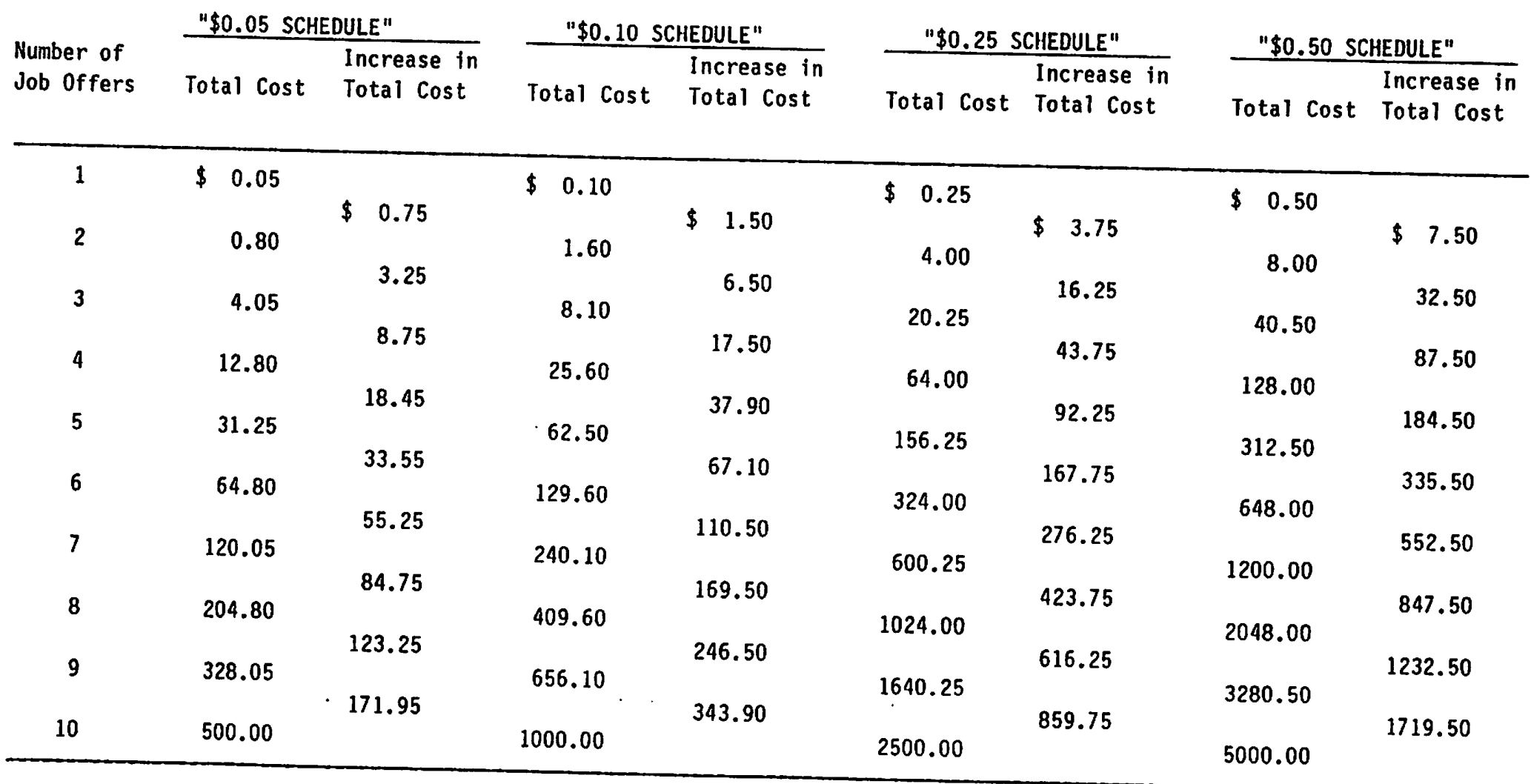


TABLE A6

Experimental Design: Training Session

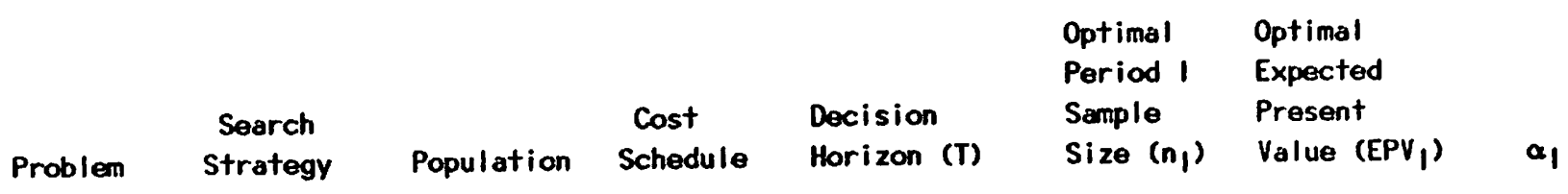

\begin{tabular}{|c|c|c|c|c|c|c|c|}
\hline 1 & vSs & BETAI & $\$ 1.00 n$ & 4 & 3 & $\$ 15.615$ & - \\
\hline 2 & SEQ & BETAI & $1.00 \mathrm{n}$ & 4 & 1 & 17.053 & 9.2 \\
\hline 3 & VSS & BETA2 & $0.25 n$ & 4 & 9 & 15.429 & - \\
\hline 4 & SEQ & BETA2 & $0.25 n$ & 4 & 1 & 11.538 & 33.7 \\
\hline 5 & vSS & BETA3 & $0.50 n^{4}$ & 8 & 1 & 15.153 & - \\
\hline 6 & FSS & BETA3 & $0.50 n^{4}$ & 8 & 1 & 13.461 & 12.6 \\
\hline 7 & VSS & BETA2 & $0.50 n^{4}$ & 6 & 1 & 19.750 & - \\
\hline 8 & FSS & BETA2 & $0.50 n^{4}$ & 6 & 1 & 18.667 & 5.8 \\
\hline 9 & VSS & BETA4 & $0.25 n$ & 4 & 5 & 3.953 & - \\
\hline 10 & SEQ & BETA4 & $0.25 n$ & 4 & 1 & 3.386 & 16.7 \\
\hline 11 & vSS & BETA3 & $0.05 n^{4}$ & 8 & 2 & 17.008 & - \\
\hline 12 & FSS & BETA3 & $0.05 n^{4}$ & 8 & 2 & 16.230 & 4.8 \\
\hline 13 & vSS & BETAI & $0.05 n^{4}$ & 4 & 2 & 18.085 & - \\
\hline 14 & SEQ & BETAI & $0.05 n^{4}$ & 4 & 1 & 16.640 & 8.7 \\
\hline
\end{tabular}


TABLE A7

Binomial Test Results: SEQ Decision Errors

Number of Observations $=600$

\begin{tabular}{|c|c|c|c|c|}
\hline \multirow{2}{*}{$\begin{array}{l}\text { Perceptive } \\
\text { Threshold } \\
\text { in Cents } \\
\text { or Percent }\end{array}$} & \multicolumn{2}{|c|}{$\begin{array}{c}\text { Foregone } \\
\text { Expected } \\
\text { Income }\end{array}$} & \multicolumn{2}{|c|}{$\begin{array}{l}\text { Percent Foregone } \\
\text { Expected } \\
\text { Income }\end{array}$} \\
\hline & \% Fail & Probability & $\%$ Fail & Probability \\
\hline 1 & 8 & 0.000 & 7 & 0.000 \\
\hline 2 & 8 & 0.000 & 7 & 0.000 \\
\hline 3 & 8 & 0.000 & 7 & 0.000 \\
\hline 4 & 8 & 0.000 & 6 & 0.000 \\
\hline 5 & 8 & 0.000 & 6 & 0.000 \\
\hline 6 & 7 & 0.000 & 6 & 0.000 \\
\hline 7 & 7 & 0.000 & 6 & 0.000 \\
\hline 8 & 7 & 0.000 & 5 & 0.000 \\
\hline 9 & 7 & 0.000 & 4 & 0.000 \\
\hline 10 & 7 & 0.000 & 4 & 0.000 \\
\hline 11 & 7 & 0.000 & 4 & 0.000 \\
\hline 12 & 7 & 0.000 & 4 & 0.000 \\
\hline 13 & 7 & 0.000 & 4 & 0.000 \\
\hline 14 & 7 & 0.000 & 4 & 0.000 \\
\hline 15 & 7 & 0.000 & 3 & 0.000 \\
\hline 16 & 7 & 0.000 & 3 & 0.000 \\
\hline 17 & 7 & 0.000 & 3 & 0.000 \\
\hline 18 & 7 & 0.000 & 3 & 0.000 \\
\hline 19 & 7 & 0.000 & 3 & 0.000 \\
\hline 20 & 7 & 0.000 & 3 & 0.000 \\
\hline 21 & 7 & 0.000 & 3 & 0.000 \\
\hline 22 & 7 & 0.000 & 3 & 0.000 \\
\hline 23 & 7 & 0.000 & 3 & 0.000 \\
\hline 24 & 7 & 0.000 & 3 & 0.000 \\
\hline 25 & 7 & 0.000 & 3 & 0.000 \\
\hline
\end{tabular}


TABLE A8

Binomial Test Results: VSS Decision Errors Number of Observations $=1650$

\begin{tabular}{|c|c|c|c|c|}
\hline \multirow{2}{*}{$\begin{array}{l}\text { Perceptive } \\
\text { Threshold } \\
\text { in Cents } \\
\text { or Percent }\end{array}$} & \multicolumn{2}{|c|}{$\begin{array}{l}\text { Foregone } \\
\text { Expected } \\
\text { Income }\end{array}$} & \multicolumn{2}{|c|}{$\begin{array}{l}\text { Percent Foregone } \\
\text { Expected } \\
\text { Income }\end{array}$} \\
\hline & \% Fail & Probability & \% Fail & Probability \\
\hline 1 & 20 & 0.000 & 19 & 0.000 \\
\hline 2 & 20 & 0.000 & 19 & 0.000 \\
\hline 3 & 20 & 0.000 & 18 & 0.000 \\
\hline 4 & 20 & 0.000 & 18 & 0.000 \\
\hline 5 & 19 & 0.000 & 17 & 0.000 \\
\hline 6 & 19 & 0.000 & 17 & 0.000 \\
\hline 7 & 19 & 0.000 & 16 & 0.000 \\
\hline 8 & 19 & 0.000 & 16 & 0.000 \\
\hline 9 & 19 & 0.000 & 16 & 0.000 \\
\hline 10 & 19 & 0.000 & 15 & 0.000 \\
\hline 11 & 19 & 0.000 & 15 & 0.000 \\
\hline 12 & 19 & 0.000 & 14 & 0.000 \\
\hline 13 & 19 & 0.000 & 14 & 0.000 \\
\hline 14 & 19 & 0.000 & 13 & 0.000 \\
\hline 15 & 19 & 0.000 & 13 & 0.000 \\
\hline 16 & 19 & 0.000 & 13 & 0.000 \\
\hline 17 & 19 & 0.000 & 12 & 0.000 \\
\hline 18 & 19 & 0.000 & 12 & 0.000 \\
\hline 19 & 19 & 0.000 & 11 & 0.000 \\
\hline 20 & 18 & 0.000 & 11 & 0.000 \\
\hline 21 & 18 & 0.000 & 10 & 0.000 \\
\hline 22 & 18 & 0.000 & 9 & 0.000 \\
\hline 23 & 18 & 0.000 & 9 & 0.000 \\
\hline 24 & 18 & 0.000 & 8 & 0.000 \\
\hline 25 & 18 & 0.000 & 8 & 0.000 \\
\hline
\end{tabular}


TABLE A9

Binomial Test Results: VSS Sampling Errors

Number of Observations $=450$

\begin{tabular}{|c|c|c|c|c|}
\hline \multirow{2}{*}{$\begin{array}{l}\text { Perceptive } \\
\text { Threshold } \\
\text { in Cents } \\
\text { or Percent }\end{array}$} & \multicolumn{2}{|c|}{$\begin{array}{l}\text { Foregone } \\
\text { Expected } \\
\text { Income }\end{array}$} & \multicolumn{2}{|c|}{$\begin{array}{l}\text { Percent Foregone } \\
\text { Expected } \\
\text { Income }\end{array}$} \\
\hline & \% Fail & Probability & $\%$ Fail & Probability \\
\hline 1 & 39 & 0.000 & 38 & 0.000 \\
\hline 2 & 39 & 0.000 & 36 & 0.000 \\
\hline 3 & 38 & 0.000 & 24 & 0.000 \\
\hline 4 & 38 & 0.000 & 22 & 0.000 \\
\hline 5 & 38 & 0.000 & 21 & 0.000 \\
\hline 6 & 38 & 0.000 & 17 & 0.000 \\
\hline 7 & 38 & 0.000 & 11 & 0.000 \\
\hline 8 & 38 & 0.000 & 11 & 0.000 \\
\hline 9 & 38 & 0.000 & 10 & 0.000 \\
\hline 10 & 38 & 0.000 & 10 & 0.000 \\
\hline 11 & 37 & 0.000 & 9 & 0.000 \\
\hline 12 & 36 & 0.000 & 7 & 0.000 \\
\hline 13 & 36 & 0.000 & 4 & 0.000 \\
\hline 14 & 36 & 0.000 & 4 & 0.000 \\
\hline 15 & 36 & 0.000 & 4 & 0.000 \\
\hline 16 & 36 & 0.000 & 4 & 0.000 \\
\hline 17 & 36 & 0.000 & 4 & 0.000 \\
\hline 18 & 36 & 0.000 & 4 & 0.000 \\
\hline 19 & 34 & 0.000 & 4 & 0.000 \\
\hline 20 & 34 & 0.000 & 3 & 0.000 \\
\hline 21 & 32 & 0.000 & 1 & 0.000 \\
\hline 22 & 32 & 0.000 & 1 & 0.000 \\
\hline 23 & 32 & 0.000 & 1 & 0.000 \\
\hline 24 & 32 & 0.000 & 1 & 0.000 \\
\hline 25 & 32 & 0.000 & 1 & 0.000 \\
\hline
\end{tabular}

